\title{
WATER RESOURCES MANAGEMENT IN THE WATERSHED OF VOLVI LAKE
}

\author{
C. TZIMOPOULOS* \\ A. ZEIBEKI \\ P. GINIDI \\ C. EVANGELIDES
}

Selected from papers presented in $9^{\text {th }}$ International Conference on Environmental Science and Technology (9CEST2005) 1-3 September 2005, Rhodes island, Greece

\author{
Aristotle University of Thessaloniki \\ Department of Rural and Surveying Engineering \\ Division of Transportation and Hydraulics Engineering \\ 54124 Thessaloniki - Greece
}

*to whom all correspondence should be addressed e-mail: tzimop@vergina.eng.gr

\begin{abstract}
The decrease of available water resources, the water quality degradation as well as the rapid increase of population combined with the growth of human activities, impose today the development of a science that concerns the Management of Water Resources. Lake Volvi faces a lot of problems, the most important being the water level drop, which is mostly due to the big quantities of water flowing through to Rihios River and to the wrong management of irrigation water. The study area of the present research consists of the watershed of Lake Volvi, situated in Northern Greece, $39 \mathrm{~km}$ away from the city of Thessaloniki. The objective of this study is the estimation of the water balance of the hydrologic basin of Lake Volvi with a Corporate Management program, using Visual Fortran and the creation of scenarios for better management of the water resources of the region. Lake Volvi is situated next to Lake Koronia, both of them belonging to a wider region that forms the geological basin of Mygdonia. Lake Volvi is the recipient of the water draining from Lake Koronia. The water that drains from Lake Volvi is discharged into the gulf of Strymonikos through Rihios River. Firstly, a close analysis is attempted for the estimation of the water balance of the entire hydrologic basin of Lake Volvi with the method of Turc, which is used widely throughout the world. Next, in order to simulate the lake, an administrative model is used, written in Visual Fortran. A rational management of the hydrological elements of the region is attempted with the creation of four alternative scenarios. After the execution of the Corporate Management program, the results show that the main problem for Lake Volvi is the water leaking to Rihios River. Moreover, the research also shows that it is important to reduce the water used for irrigation. As a final result, it is an imperative need to develop water resources management plans for the restoration of the entire region.
\end{abstract}

KEYWORDS: water mass balance, geostatistic analysis, evapotranspiration, restoration.

\section{INTRODUCTION}

The present paper focuses on the estimation of the water mass balance during the time period 1995-2001 throughout the whole area of the hydrological basin. For this purpose a customized management model has been, planed, developed and executed in a satisfactory way, using Visual Fortran. Values of precipitation and temperature, from 1964 to 2002 were collected from 13 different stations, from which 10 were located inside the watershed area. A geostatistic analysis was performed, in order to obtain the values of the evapotranspiration, precipitation and temperature in every single position of the area. After the calibration of the model for the period 1995-1999 a forecast up to year 2002 was 
made. In order to estimate the water mass balance and to evaluate the impact of watershed structures and irrigation water usage, a series of management scenarios, were formulated. These scenarios take into consideration the climatic parameters, the constructions and the water utilization. This section presents a brief description of four scenarios and relative comparisons of the simulated results.

Mygdonia basin is a common case of today's water resources problem. The fact that it contains an extensive plain, which is being intensively cultivated, has led to a remarkable increase of water demand, disturbing thus the hydrological balance of the area (Chatzipetros and Pavlides, 1998).

Mygdonia watershed is located in Northern Greece and lies in the zone between Galikos River and Strymonikos gulf (Figure 1). The basin can be subdivided in two parts (Psilovikos, 1977): the eastern part, involving the basin of Volvi, and the western one, consisting of Lagadas basin. The whole area is about $2036 \mathrm{~km}^{2}$.

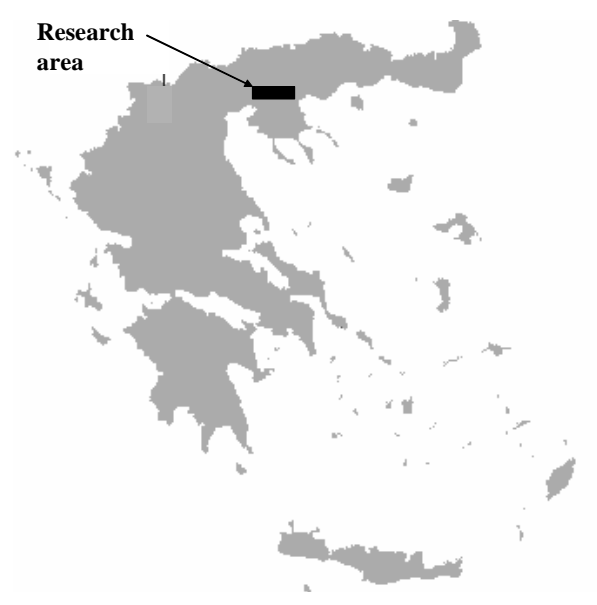

Figure 1. The study area

The most important problem of Lake Volvi is the lowering of the water level. The most important natural cause is the discharge through Rihios River to Strymonikos gulf. Thus, a very interesting water resources management problem is formed in the area that has to be planed, developed and examined within an integrated framework.

\section{WATER BALANCE ESTIMATION}

A close analysis is attempted for the estimation of the water mass balance of the Volvi basin. This estimation was based on data of precipitation, temperature, evapotranspiration, shallow and deep aquifer.

Direct surface-runoff as well as temperature data was estimated during the 1963-1979 period according to thirteen different stations (Figure 2).

Considering the lack of substantial precipitation data as far as the time period 1980-2002 is concerned, the linear regression method was utilized to evaluate existing values compared to values recorded by the meteorological station of Thessaloniki (AUTH). The coefficient of correlation turned out to be higher than 0.7 , which implies strong statistical results and so existing data was supplemented by estimated data.

Temperature data was also obtained, using the above method. Taking into account that for some meteorological stations available data are non-existent, a linear regression method between altitudes and temperature is applied in order to estimate all the necessary temperature elements. 


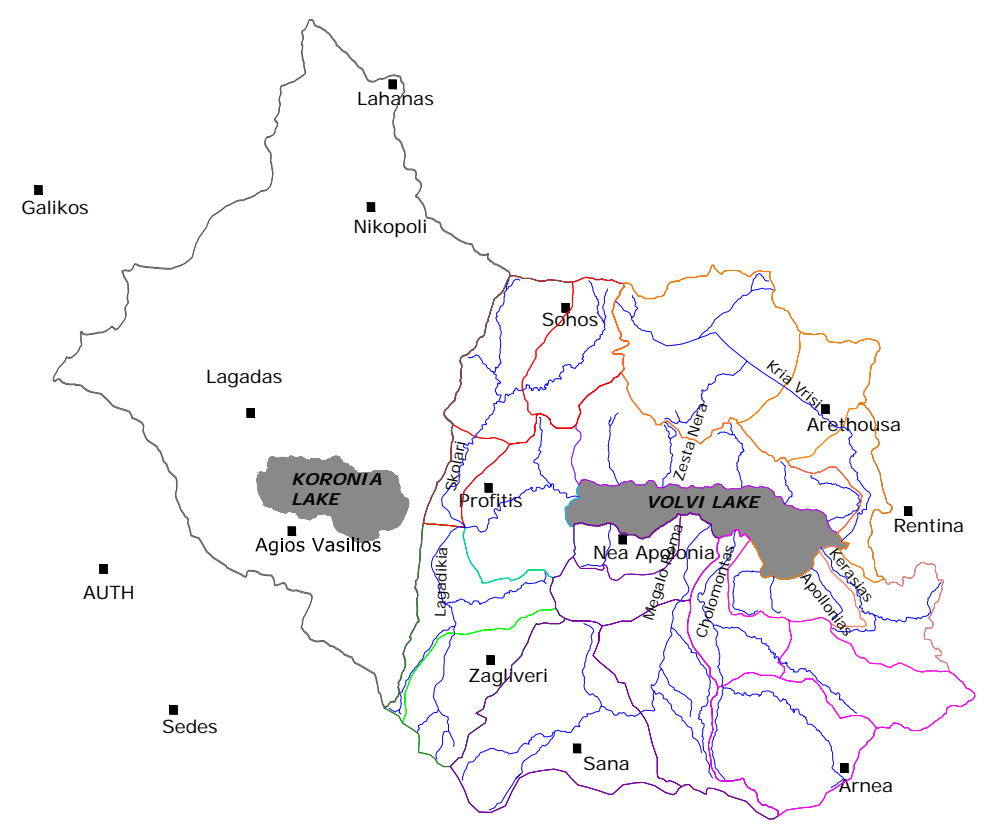

Figure 2. Hydrological basin of Mygdonia and the meteorological stations

Using the resulting values and applying geostatistic analysis, temperature and precipitation contours are drawn, enabling the estimation of data in every single point of the study area. Contouring illustration for precipitation and temperature values, corresponding to the time period1999-2000, is indicated in figure 3 and 4 respectively.

Actual evapotranspiration calculations are achieved, using modified Turc equation (Turc, 1955) providing results for every single hydrological time period, as follows:

$$
\mathrm{E}_{\mathrm{t}}=\frac{\mathrm{P}}{\sqrt{0.9+\left(\frac{\mathrm{P}}{\mathrm{L}}\right)^{2}}}
$$

where $\mathrm{P}$ is the precipitation in $\mathrm{mm}, \mathrm{L}=300+25 \overline{\mathrm{T}}+0.05 \overline{\mathrm{T}}^{3}, \overline{\mathrm{T}}=\frac{\sum \mathrm{P}_{\mathrm{i}} \mathrm{T}_{\mathrm{i}}}{\sum \mathrm{P}_{\mathrm{i}}}$ and $\mathrm{T}$ is the temperature in ${ }^{\circ} \mathrm{C}$. Equation 1 is widely used throughout the world, especially in regions where a relative uncertainty exists, concerning the available data.

The whole area was divided into smaller basins according to the topographical and hydrological structure in order to obtain a better picture of the hydrological system. Water mass balance is considered to each separate basin, estimating the evapotranspiration effects as well as the inflows, which is mainly the recharge by precipitation.

The basins of the main streams have been divided into smaller ones, taking into account different percolation coefficients thus enabling a more detailed stream flow simulation (Figure 5). According to this schematic diagram, where each sub-basin corresponds to a calculation junction, a Visual Fortran program was formulated. Data in each junction includes:

- The total volume of the inflow water, coming from precipitation and recharge procedures.

- Evapotranspiration values.

- Percolation coefficient in every individual hydrological sub-basin.

- Runoff resulting as the algebraic sum of the above elements. 


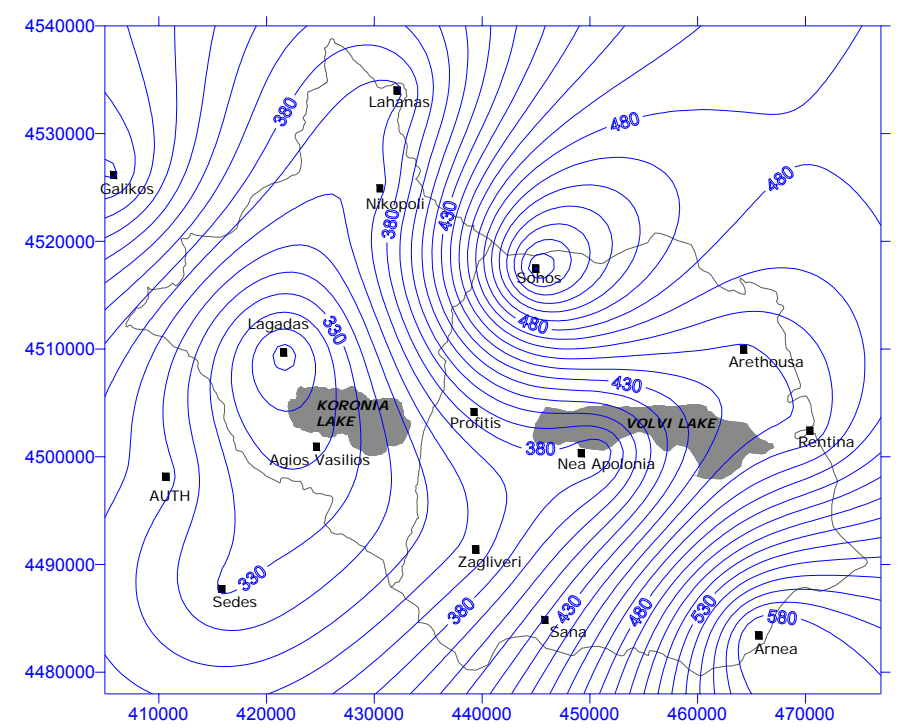

Figure 3. Precipitation illustration for time period 1999-2000

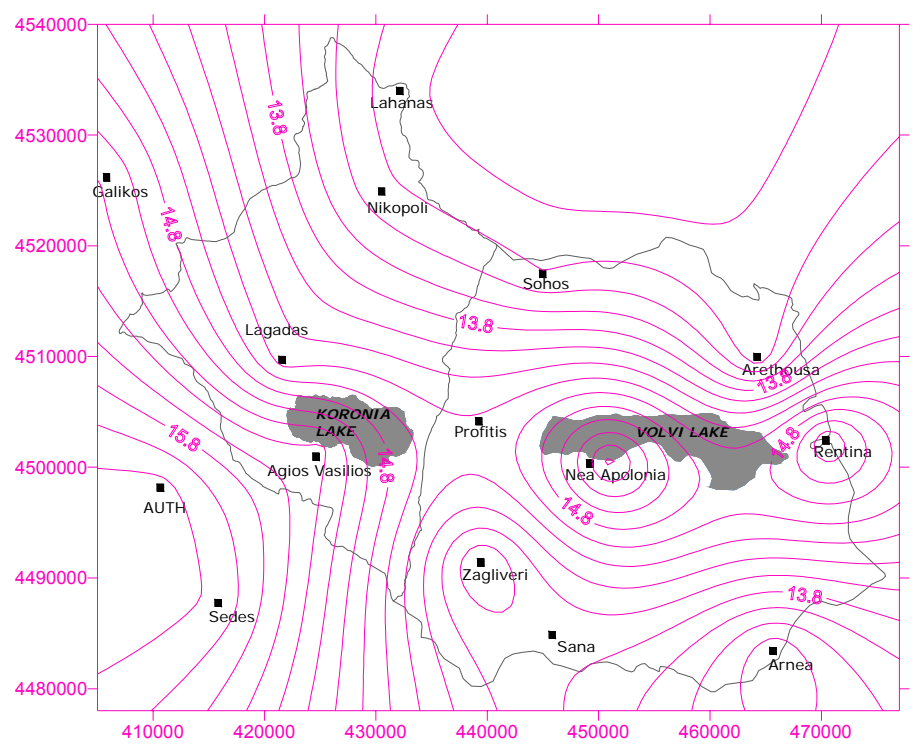

Figure 4. Temperature illustration for time period 1999-2000

Apart from the stream flow the model took into consideration water demand for irrigation, industrial and water supply as a separate junction.

\section{SCENARIOS}

A water resources management of the basin should take into consideration all the possible alternative solutions, design and develop all the alternative scenarios, set the priorities, evaluate each scenario based on these priorities and finally choose the best appropriate solution.

The basins of each mainstream flow have been divided into smaller ones, enabling a more detailed stream flow simulation as well as the use of different coefficients of deep percolation (Figure 5). 


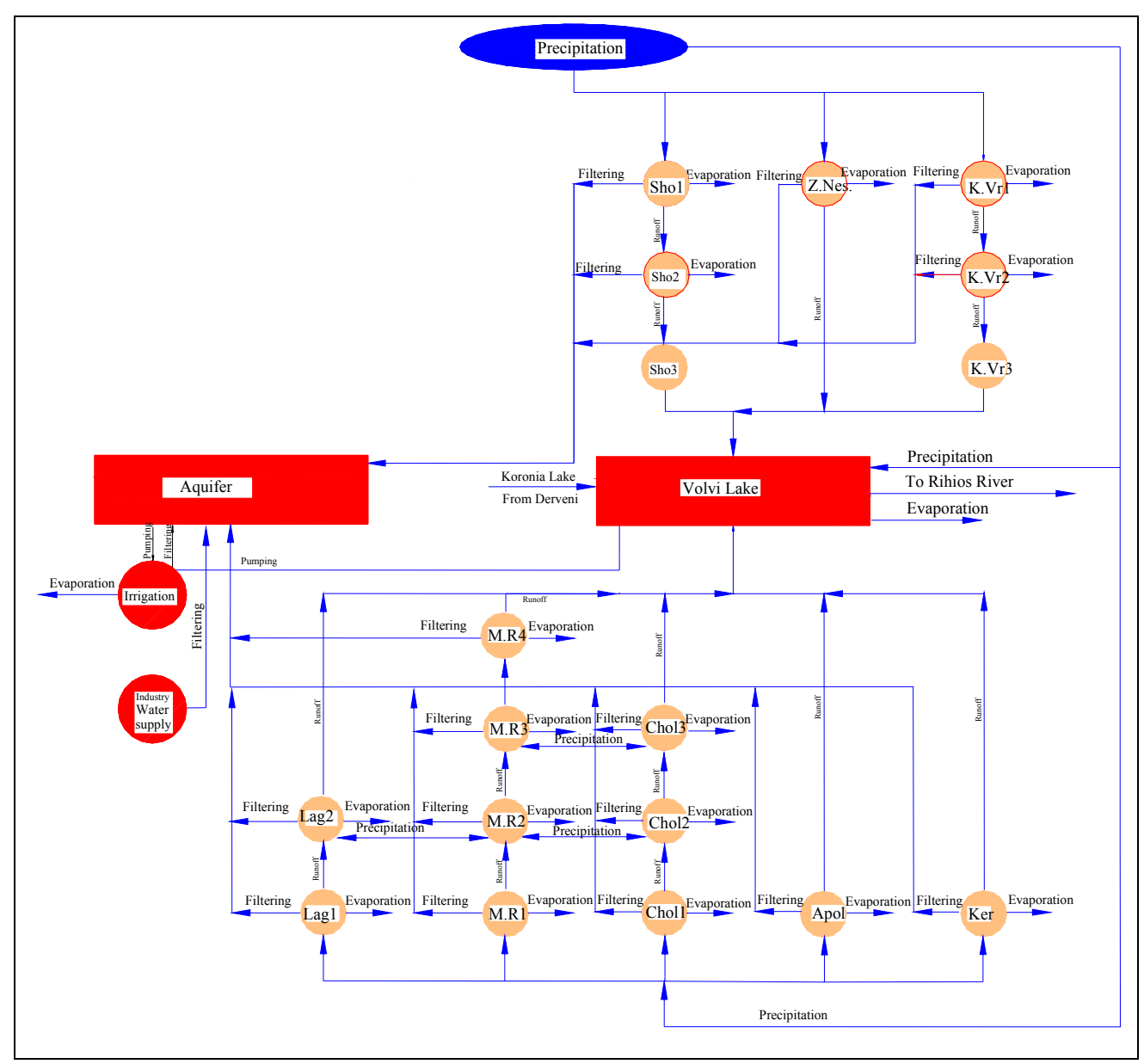

Figure 5. Schematic diagram of hydrological basin of Volvi region

Based on the previous assumptions, alternative scenarios, aiming to the best possible restoration of Volvi Lake are formulated. This section presents a brief description of four scenarios and relative comparisons of simulated results:

1. The simulation of Lake Volvi hydrological process for the time period of 19951999 is attempted. Simulation results of the water lake in conjunction with time period can be illustrated in Figure 6.

2. Another simulation of Lake Volvi hydrological process for the time period of 19952001 is also attempted. The difference from the previous scenario is that after the year of 2000 we consider a reduction of the discharge of the torrents of Lagadikia and Sholari up to $64 \%$, and a decrease of Rihios River discharge to $500.000 \mathrm{~m}^{3}$ yearly. Results are illustrated in the Figure 7.

3. The simulation of Lake Volvi hydrological process for the time period of 19952001 is examined, but in this case the full diversion of Lagadikia and Sholari torrents is taken into account after the year 2000. Simulation results are illustrated in Figure 8.

4. In this simulation, the Lake Volvi hydrological process for the time period of 19951999 is attempted, considering that the discharge of Rihios River is $500.000 \mathrm{~m}^{3}$ on a yearly basis. Water lake fluctuation is illustrated in Figure 9. 


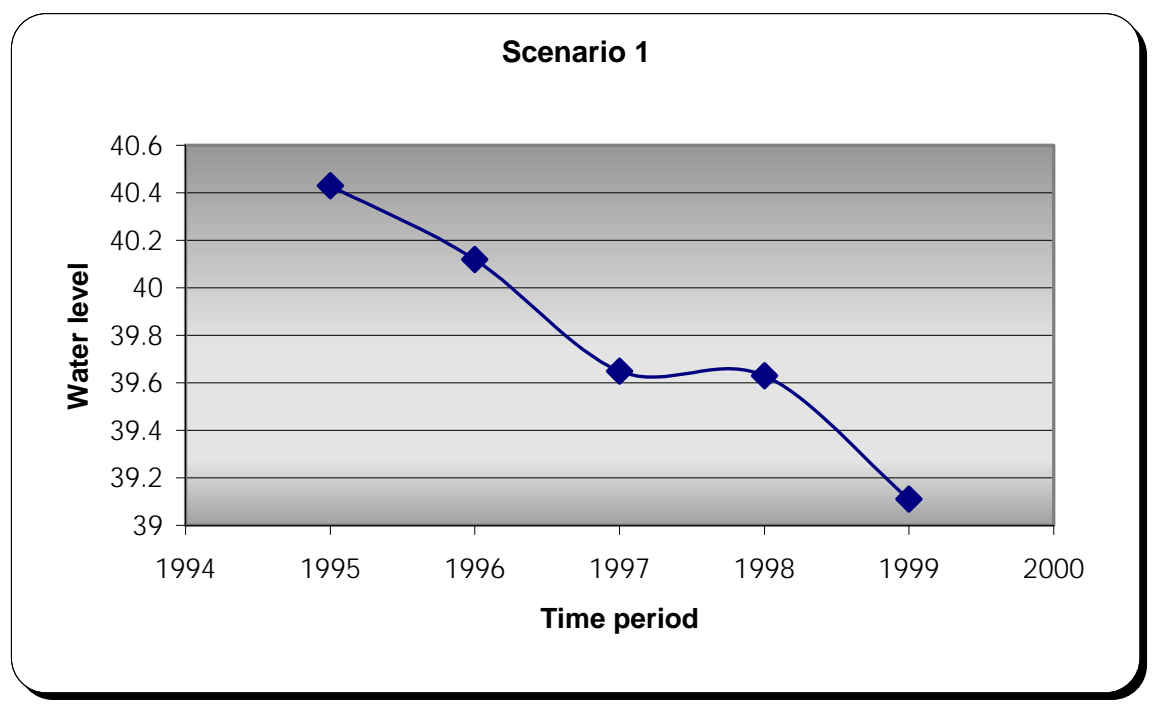

Figure 6. Water lake fluctuation for the time period of 1995-1999

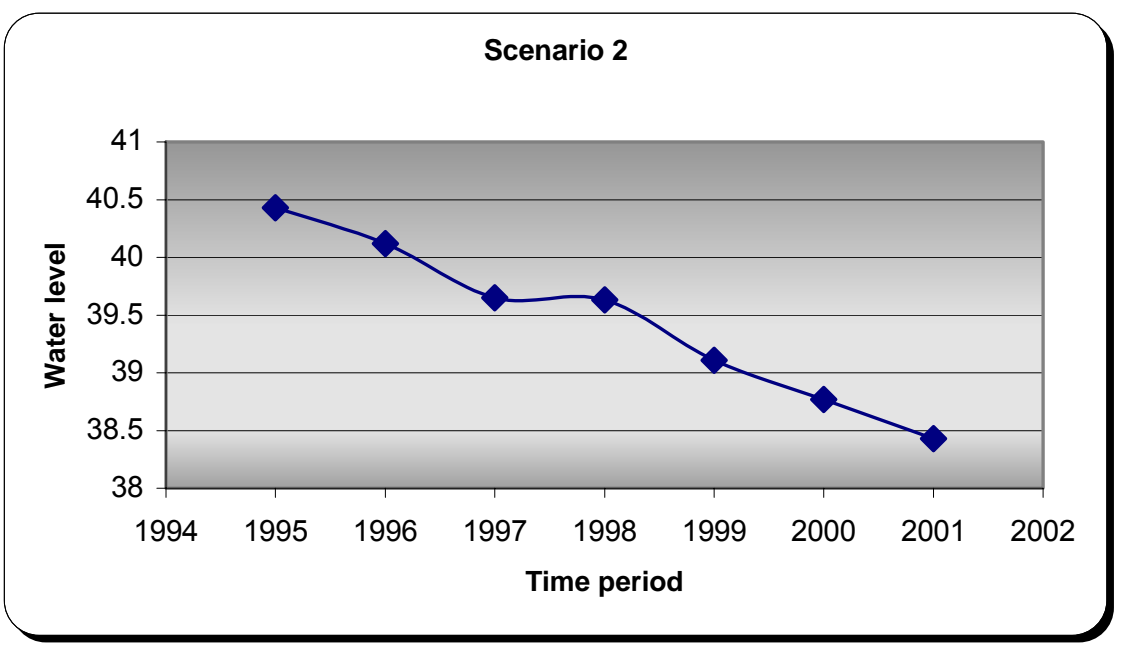

Figure 7. Water lake fluctuation for the time period of 1995-2001

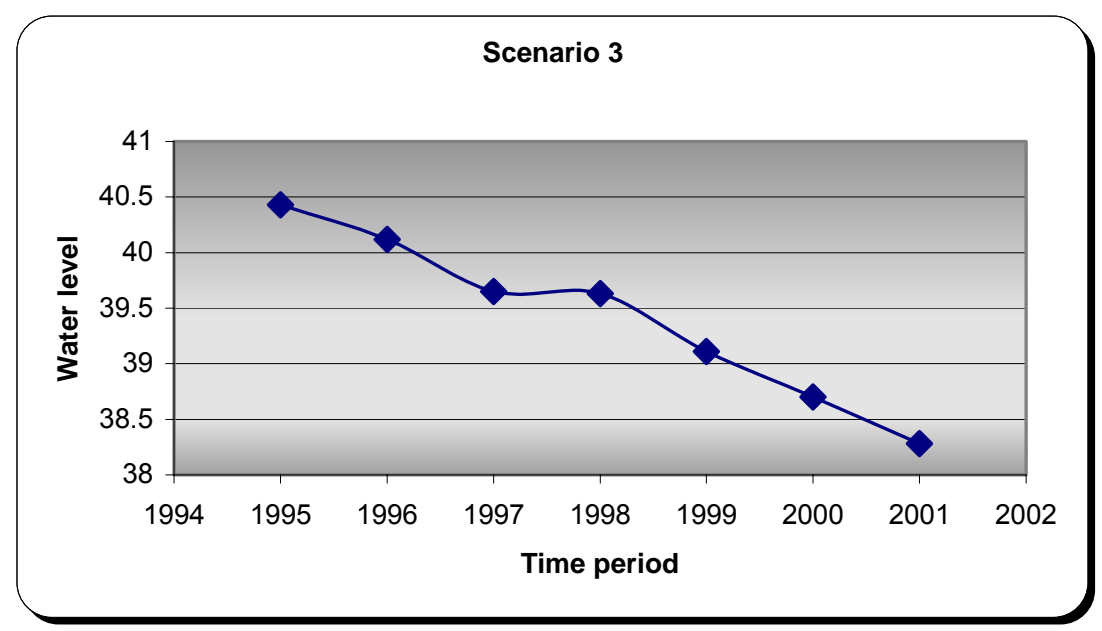

Figure 8. Water lake fluctuation in the case of Lagadikia and Sholari full diversion for the time period of 2000-2001 


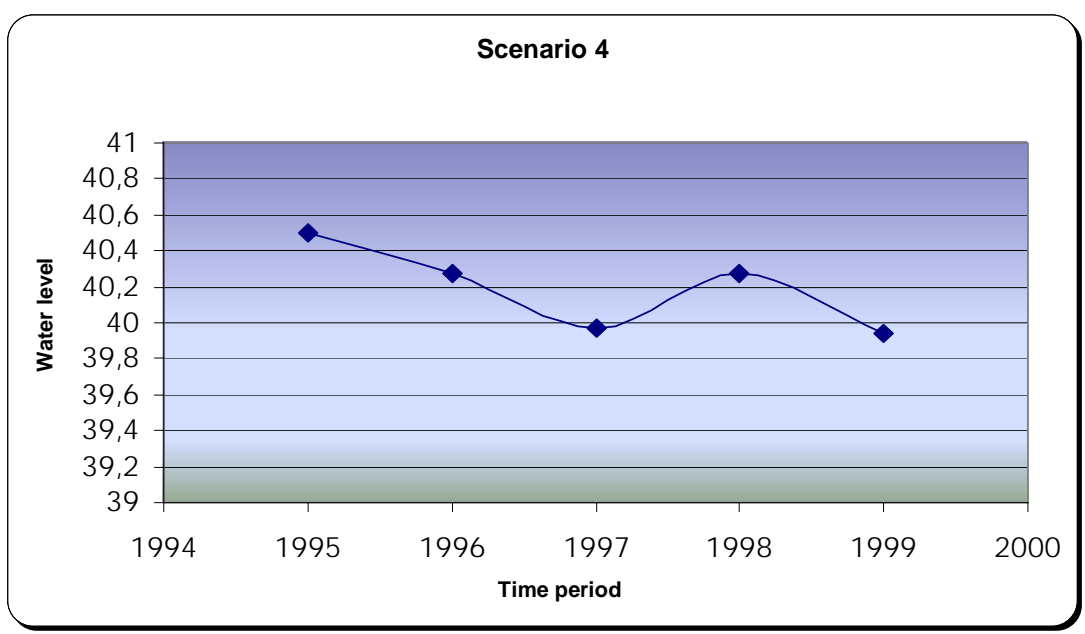

Figure 9. Water lake fluctuation considering the discharge of Rihios River for the time period of 1995-1999

\section{CONCLUSIONS}

The Visual Fortran program was calibrated and verified using all the available streamflow, irrigation water use, and watershed structure parameters. Through the application of the model, four hypothetical management scenarios, assuming operational criteria, were formulated. Therefore, the following measures turned out to be the most appropriate ones, in order to achieve the rise of water table and the reduction of irrigation demand in the region.

- Construction of a dam at the Eastern part of Lake Volvi which would give the possibility to control the quantity of water flowing through to Rihios River, and keeping the water mass balance of the lake in satisfactory level.

- Imposition of a rational and functional form of charge and recording the exact irrigation demand.

- Apart from the hydrological restoration, measures concerning the improvement of the quality of Lake Volvi water should be taken into consideration. The existing industries as well as the extended usage of pesticides have created a big pollution problem in the region, resulting of the elimination of the vital existence.

It is obvious that these measures, under certain conditions and sustainable manipulation, could solve the present water shortage problem of the area, resulting thus to the restoration of Lake Volvi to its initial state.

\section{REFERENCES}

Chatzipetros, A. and Pavlides, S. A (1998) 'Quantitative Morphotectonic Approach to the study of active faults, Mygdonia basin, Northern Greece', $8^{\circ}$ International feast of Greek Geological Company, Patra, Greece.

Mylopoulos I., Latinopoulos P. and Theodosiou N. (1991) 'A combined use of simulation and optimization techniques in the solution of aquifer restoration problems, In: Water pollution, Measuring and Prediction', L.C. Wrobel and C.A. Brebbia (Eds), Pro. First Inter. Conference on Water Pollution, Southampton.

Psilovikos A. (1997) 'Geographical development of watershed and Lake Mygdonia (Lagada-Volvi)', Phd thesis, AUTH, Greece.

Turc, L. (1955) 'Le bilan d' eau des sols. Relations entre les precipitations, I' evaporation, et l' ecoulement', Ann. Agr., 6, 5-131.

Veranis N., Katirtzoglou K. (2003) 'Water mass balance in the hydrological basin of Lake Koronia', Institute of Geological and Mineral Researches, Greece. 